\title{
Oral health screening should be routine in professional football: A call to action for sports and exercise medicine (SEM) clinicians.
}

Ian Needleman ${ }^{1}$, Paul Ashley ${ }^{1}$, Richard Weiler ${ }^{2,3,4}$ \& Steve McNally ${ }^{5}$

${ }^{1}$ Centre for Oral Health and Performance, UCL Eastman Dental Institute, London, UK

${ }^{2}$ West Ham United Football Club, Sports Medicine \& Sports Science Department, West Ham United FC Training Ground, Chadwell Heath, Essex, UK

${ }^{3}$ University College London Hospitals NHS Foundation Trust \& UCLH Institute of Sport, Exercise and Health, London, UK

${ }^{4}$ The FA Centre for Disability Football Research, Burton-Upon-Trent, UK

${ }^{5}$ Football Medicine \& Science Department, Manchester United Football Club, Manchester, UK

\section{8 words}

In the January 2016 issue of BJSM, we showed that professional footballers in the UK have poor oral health and this is associated with negative self-reported impacts on training, performance and wellbeing (1). Since more than $90 \%$ of each senior squad participated in the study, we can be confident that the results represent a true picture. These findings are also consistent with data we collected during the London 2012 Olympic Games and a recent systematic review (2). The emerging picture is of poor oral health in elite sport with important impacts on self-reported performance. In this call to action for oral health screening in professional football we; (i) place players' oral health alongside UK norms, (ii) make the case that footballers are at high risk of poor oral health, and (iii)set out the case for screening and how this could lead to improved oral health in professional football.

\section{How good is footballers' oral health?}

Oral health is not simply absence of disease. It should positively contribute to the wellbeing and functioning of individuals (and societies) including performance of elite athletes. A side by side comparison of the most recent UK oral health data (3) with professional footballers for age 16-24 years shows worse oral health: dental caries $30 \%$ vs $38 \%$, moderate toothwear (loss of enamel and dentine without caries) $4 \%$ vs. $20 \%$, and gingivitis $50 \%$ vs. $82 \%$ respectively. If compared only with those attending the dentist regularly, the gulf would be much greater. $20 \%$ of footballers report negative impact of their oral health on quality of life and $7 \%$ consider it impairs their performance. 


\section{Should professional footballers be considered at high risk of poor oral health?}

Consider two lines of evidence. First, the best available evidence suggests that footballers present with levels of caries, dental erosion and periodontal diseases that confer a high treatment burden with longterm implications for management. Second, current evidence-based public health guidance identifies these disease levels as requiring a high risk approach to disease prevention (4).

\section{What are the implications for sport and exercise medicine clinicians?}

Given that footballers are at high risk of poor oral health, three closely related action items arise;

1. Introduction of periodic oral health screening

2. Universal high risk prevention/risk mitigation

3. Integration of oral health promotion within overall athlete-care

The classic principles guiding early disease detection/screening (5) are well met for oral health and perhaps to a greater degree than other musculoskeletal 'screening' practices that are more commonly undertaken in professional football. We recommend that screening should be conducted by a dentist twice per year, including in the pre-season window. This allows the identification and provision for early treatment as well as the opportunity to encourage adherence to preventive care. The costs likely involve one-two days of a dentist's time to screen a senior squad and should be compared with the expense per player of loss from training or matches due to oral health problems.

\section{A universal prevention strategy vs a targeted approach}

An enhanced universal preventive strategy should be adopted for all footballers rather than limiting to individuals with identified disease (6). As some challenges to oral health such as carbohydrate-containing sport supplements may be unavoidable for professional athletes, we recommend a strategy of disease prevention and risk mitigation $(2,4)$. These measures include:

- using of higher concentration fluoride toothpastes (2,800 and 5,000 ppm fluoride) and mouthrinses,

- avoiding carbohydrate when not required for performance

- effective daily oral hygiene, particularly between the teeth 
Implementation could be delivered by a dentist, dental care professional (e.g. dental hygienist or dental health educator) or other trained member of the medical team. For sustained improvement, oral health promotion should be integrated and delivered as part of overall health promotion within professional football. The benefits of integration would be little reducing need for resources and ownership and reinforcement of key messages across support staff.

Clearly, a different approach to oral healthcare in professional football is required. There will need to be leadership at all levels including international sporting federations, national organisations and club-level sport. Furthermore, responsibility for effective change will include those delivering healthcare including SEM physicians, nutritionists and physiotherapists.

Is this a case of too much medicine (7)? We believe not. Oral diseases are prevalent in sport, early treatment is simple and prevention works. Embedding this into current health service delivery would need very modest investment [as above]. Oral health screening and promotion should begin at the earliest stage of a player's career (e.g. when commencing a Youth Scholarship) and could deliver 'best buy for health' (8), wellbeing and performance in football of any intervention.

\section{References}

1. Needleman I, Ashley P, Meehan L, et al. Oral health in UK Professional Football. British Journal of Sports Medicine 2016; 50 (1) ; 000-000 in press doi:10.1136/bjsports-2015-094953

2. Needleman I, Ashley P, Fine P, et al. Consensus statement: Oral Health and elite sport performance. British Journal of Sports Medicine 2015; 49: 3-6

3. Fuller E, Stele J, Watt R \& Nuttall N. 1. Oral Health and function- a report from the Adult Dental Health Survey 2009. The Health and Social Care Information Centre. http://www.hscic.gov.uk/catalogue/PUB01086/adul-dent-heal-surv-summ-them-the1-2009-rep3.pdf Accessed 5 November 2015

4. Public Health England. Delivering better oral health. An evidence-based toolkit. $3^{\text {rd }}$ Edition. 2014. https://www.gov.uk/government/publications/delivering-better-oral-health-an-evidence-basedtoolkit-for-prevention. Accessed 6 November 2015

5. Wilson JMG \& Jungner G. Principles and practice of screening for disease. World health Organization. 1968 Geneva http://apps.who.int/iris/bitstream/10665/37650/1/WHO PHP 34.pdf Accessed 6 November 2015

6. Rose G. Sick individuals and sick populations. International Journal of Epidemiology 1985; 14: 32-38. 
7. Moynihan R, Glasziou P, Woloshin S, et al. Winding back the harms of too much medicine. British Medical Journal 2013; $346: f 1271$

8. Morris J. Exercise in the prevention of coronary heart disease: today's best buy in public health. Medicine \& Science in Sports \& Exercise 1994; 26: 807-814 